urge that the schoolboy's characterization actually holds of me when, for example, I believe that Thursday falls on the fourth despite knowing that Tuesday falls on the first. This hardly counts as a vindication of the possibility of faith, however.

${ }^{3}$ Though the notion of conclusive reasons gets hedged somewhat on p. 37 .

JeffKasser

Department of Philosophy

Colby College

Waterville, ME 04901

j_kasser@colby.edu

\title{
Evidence-Based Practice: Logic and Critical Thinking in Medicine
}

\section{Milos Jenicek and David L. Hitchcock}

Dubuque: Kendall/Hunt, 2001. Pp. ix, 1-215. Paper. ISBN 0-7872-8156-5.

\$62.95 USD.

\section{Reviewed by Peter A. Facione}

Physicians and philosophers of note agree that a book aimed at explaining how logic and critical thinking can improve medical practice is much needed. They agree that such a book should emphasize an evidence-based approach to practice because "our entire professional life is a wild world of arguments-meant in the sense of exchanges between people sharing information and giving reasons which form the bases, grounds, and warrants for their claims. Since "logic and critical thinking is about rational uses of evidence," a valuable preparation for professional practice would naturally include learning "the proper uses of evidence in daily practice and research." This text book, co-authored by two practicing professionals, one a physician and the other a philosopher, sets out to be that book. The authors explain in their preface that the book is intended to be "a textbook that should guide its readers in choosing the objectives of teaching, what to teach, how to teach it, and what to retain from the whole message for better practice, for better research, and, most important, for the benefit of the patient." Given that objective, of being a guide in choosing the objectives of teaching, the book in organized into two main parts: Theory and Methodological Foundations, and Practical Applications.

The theory and methodological foundations section devotes 134 pages to four chapters. Chapter one introduces the reader to philosophy as a professional academic discipline, locates the place of logic among the branches of philosophy, and explains how philosophy seeks to apply itself in a broad array of practice fields and research areas. This chapter places good emphasis on those aspects of the application of philosophical principles which relate to medicine, including communicating 
effectively with patients, engaging in and understanding medical research, and practicing the art and the science of medicine in a logically sound, evidence-based way.

Chapter two is a précis of the standard presentation of logical thinking as might be found in any number of basic, well-conceived college courses. One expects to find sections addressing reasoning and arguments, premises and conclusions, restating arguments, distinguishing claims from warrants, backing, grounds, and qualifiers. And one is not disappointed. Toulmin's scheme for laying out arguments is nicely presented by page 30 , with diagrams and examples. This is followed by a section on detecting and reconstructing arguments found in more everyday communications and conversations as might occur between patient and health care provider. We make our way to the criteria for evaluating good reasoning and justified arguments, and complete the chapter with a fairly standard classification of fallacies.

Chapter two is one of the best, most useful, and most important chapters in the book. In the next edition of the book I would urge that this important chapter be augmented in two ways: That greater attention be given to the difference between "reasons" and "premises" in working through argument reconstruction. Transcriptions of patients explaining what leads them to their health care judgments about what to do or what to believe amply illustrate that patients give multiple independent reasons which at times lead in divergent directions. Conversations with patients often involve exploring their different reasons, some of which are presented as a single premise from which a claim is made, with warrant and backing and qualifiers implicit and unstated, and some of which involve multiple premises, but premises which are independent from those used in forming other reasons for the same conclusion. Which brings forward the second suggestion for further strengthening this already good chapter in the next edition, and that is that serious amounts of space should be spent working though excerpts of real conversations between patients and their health care provider using the Toulmin scheme. Perhaps nothing will be more beneficial toward achieving the authors' laudatory goal of improving the medical practitioners' communication skills than this. Having done this in our own research on patient health care decision making, we found this exercise to be of tremendous value in bringing forward the subtle complexities of these, at times, life and death conversations.

Chapter three devotes 30 pages to logic, running through various branches of logic, defining terms, sorting out the differences between Aristotelian Logic, Contemporary Logic, Indian Logic, uncertainty, probability, fuzzy logic, fuzzy set theory, and fuzzy reasoning wherever it may be found. Chapter four devotes its first twenty pages to providing the same services-classification, categorization, definition of terms, historical contextualization-to critical thinking. Attention is devoted here to the skills dimension and the dispositional dimension of critical thinking; the practical and purposive nature of critical thinking, and its meta-cognitive and reflective aspects. The importance of forming a considered, evidence-based, overall judgment about what to believe and what to do is properly emphasized. Except that learning about logic and about critical thinking is fun in its own right, my sugges- 
tion for the second edition of the book, whenever that comes out, is that for all practical purposes the authors might reduce this section from 50 pages to 5 pages. Learning about critical thinking is not the same as learning how to engage more effectively in critical thinking.

But, whatever they do, they must keep the second half of chapter four. Those pages are devoted to a practical example, beautifully selected and expertly taught and presented. The example is the challenge of complementary and alternative medicine. Pages 118 through 135 are masterful. The problem is thoughtfully analyzed and clarified, the arguments are laid out expertly, and the reasoning is explicated, considered, and evaluated with a level of ease and grace that truly make the case for why this book is so important to the training of medical practitioners. If they learn how to do this they will be better in all the ways the authors hope.

The first four chapters bristle with technical vocabulary. The readers who is able to internalize and integrate all of this definitional knowledge will be well equipped to discuss reasoning, logic, and critical thinking in ways that would be familiar and welcome to the current generation of practicing philosophers. Who knows, at some point this might be valuable to health care practitioners or at least to the faculty of medical and other health sciences schools who prepare these students. Laying it all out in these chapters, and repeating this program of specifying definitions and naming kinds of fallacies in the final three chapters of the book, may prove to be of great value if these ways of talking about reasoning can become common throughout the professional preparation curriculum. The reinforcement of a common vocabulary has great power to shape the culture of learning in a professional school.

Or, it may backfire. The rich array of carefully crafted concepts and subtly differentiated and nuanced semantics presented with such care by these authors may serve only to bewilder and confuse professional school faculty and students who have learning outcomes other than memorizing terminology foremost in mind. And that would be unfortunate, for the book is too important and too valuable to be set aside on that basis. This edition of the book errs if at all on the side of being too didactic. The authors may have pushed too hard to satisfy academicians in the humanities and to establish their bona fides to trained professional philosophers. In the next edition I hope they nod pleasantly toward those folks, but walk boldly in the direction of the practitioners, field testing chapters with medical school faculty in medical school classrooms to discover more precisely which theoretical frameworks and definitional distinctions are absolutely essential and which are not. My sense is that far less is needed, that our common language is quite robust, and that much more would be gained were the authors to talk more about "how" and less about "what." More exemplars of effective critical thinking pedagogy would be more effective, this reviewer hypothesizes, than talk about how to talk about critical thinking and logic.

In other words, if the aim is to present the vocabulary and theoretical domain information needed to teach effective reasoning and communication, then this part of the book achieves its goal. But if the book is indeed to be a text book, either to be used by students themselves, or by their teachers as a means to their own more effective teaching, then in its next edition it can become much stronger by engaging 
the reader in effective thinking exercises and then deconstructing those exercise in order to demonstrate effective methods of teaching for thinking, rather about thinking.

The three final chapters offer practical applications of the theoretical material which occupies the first part of the book. chapter six, on talking and listening to colleagues and patients is particularly well conceived and welcome. One small point, however. This reviewer does not accept the notion, implicit in this chapter, that patients have a different and less effective way of reasoning than do clinicians. The Chapter does not need that notion to be successful in its main goal, which is to guide clinicians toward being better able to articulate their own diagnostic reasoning and treatment plans. In the end, perpetuating the empirically questionable notion that poor health care decisions on the part of patients come about due to their being ignorant of the facts or just poor thinkers, only gets in the way of effective communication. In the next edition of the book I urge the authors to dig deeply into the question of how patients make health care decisions and what it takes for the concerned practitioner first to understand, then to effectively connect with and communicate to persons who bring complex sets of personal and family goals, emotional responses, positive and negative personal experiences with health care systems, concerns about financial and family obligations, negative community narratives about health care prognoses, varying attitudinal orientations, varying social mores and service expectations, and cultural and religious differences to the health communication context. In fact, patient decision making is probably more about those things than about facts and reasoning skills.

The two chapters not yet mentioned are chapter five, which focuses on the logic of biomedical research and how to write and read medical articles, and chapter seven which looks at how clinicians might communicate more effectively in legal and political venues. The topics addressed in both of these chapters are important and the authors should be praised for having taken them on. That said, instead of chapter five as it exists in this edition, this reviewer hopes that in the next edition the authors recommend that medical students take a good pair of graduate courses in health science research theory and methods where they learn how to do a fairminded and critically analytic literature review, how to design solid research studies on questions of significance in either basic sciences or health care practice, how to develop and validate necessary instruments and tools, how to aptly apply the appropriate quantitative and qualitative research methods, and then how to write up the results for publication. This reviewer would suggest that chapter five should be recast in the next edition to better assist faculty who teach health science research theory and methods how to incorporate more effective critical thinking pedagogies into their courses.

One final note: the authors rightly characterize critical thinking as having a skills dimension and a dispositional dimension. In the next edition this reviewer hopes that the authors will focus more on ways to strengthen those skills by exercising them and then reflecting on those exercises. And this reviewer hopes that the authors will do a lot more with the dispositions, by explaining how positive critical thinking dispositions, such as truth-seeking, are essential to successful 
research and effective communication; but that negative critical thinking dispositions, like being conceptually disorganized or intellectually indifferent, or closedminded, or biased, can be harmful not only to one's own development and maturation as a practitioner, but can lead to poorer health care options for one's patients.

In sum, this reviewer says thumbs-up to this book. It is a first attempt, and a fine one. Sure one can find flaws and infelicities, and one might prefer that more was said about this and less about that. But in the end, this is a book that needed to be written. We need more books of this kind that attempt to show how to be more effective critical thinkers in a given area of professional practice. And we need books that help the faculty of professional schools more effectively teach for thinking. If someone can do a better job with evidence-based medical practice, let them step up and do it.

Peter Facione University Provost and Professor of Philosophy Office of the Provost Loyola University Chicago 820 North Michigan Avenue Chicago, Illinois 60611

Email:pfacion@luc.edu

\section{Abduction, Reason, and Science: Processes of Discovery and Explanation}

\section{Lorenzo Magnani}

New York, Boston, Dordrecht, London, Moscow: Kluwer Academic/ Plenum Publishers, 2001. pp.xvii, 1-205. ISBN 0-306-46514-0. \$93.50 USD.

\section{Reviewed by Marcello Guarini}

In the late 1980s, Paul Churchland ${ }^{!}$, Ronald Giere ${ }^{2}$, and Paul Thagard ${ }^{3}$ started applying insights gleaned from artificial intelligence, cognitive science, and psychology to problems in the philosophy of science. Those early works were characterized by extended, introductory discussions of the science being applied to philosophical problems. Things have changed since those pioneering efforts, and Lorenzo Magnani's Abduction, Reason, and Science is an example of the change. Gone are the introductory discussions of the science. Dozens of authors from artificial intelligence, cognitive science, philosophy, and psychology are cited, and the reader is expected to have at least some familiarity with this wide range of work. As a field develops, it is not uncommon for authors to expect more of their readers, so the 